\title{
Characterization of Drug Resistance in Streptococcus parauberis Isolated from Japanese Flounder
}

\author{
Fei Meng ${ }^{1}$, Kinya Kanai ${ }^{2 *}$ and Kazuma Yoshikoshi ${ }^{2}$ \\ ${ }^{1}$ Graduate School of Science and Technology, Nagasaki University, Nagasaki 852-8521, Japan \\ ${ }^{2}$ Faculty of Fisheries, Nagasaki University, Nagasaki 852-8521, Japan
}

(Received October 3, 2008)

\begin{abstract}
Antimicrobial susceptibility of Streptococcus parauberis against nine drugs were investigated in 64 strains isolated from Japanese flounder Paralichthys olivaceus at different culture areas of western Japan, and resistance genes were determined by PCR and Southern blot hybridization. Five of the tested strains belonging to $S$. parauberis serotype I ( 44 strains) were resistant to oxytetracycline and erythromycin and were found to possess both $\operatorname{tet}(\mathrm{S})$ and $\operatorname{erm}(\mathrm{B})$ genes. Minimum inhibitory concentrations (MICs) of oxytetracycline and erythromycin were 128 and $512 \mu \mathrm{g} / \mathrm{mL}$, respectively. Southern blot hybridization analysis showed that the tet(S) gene was encoded on an 11-kb conjugative plasmid, while the erm(B) gene resided on the chromosomal DNA. All of the examined $S$. parauberis serotype II strains (20 strains) were tetracycline-resistant $(\mathrm{MIC}=32 \mu \mathrm{g} / \mathrm{mL}$ ) and were found to possess tet $(\mathrm{M})$ gene. Both int (integrase) and $x$ is (excisase) genes were also detected in all of the serotype II strains, suggesting the presence of Tn916-related element in these strains. These results present a threat of difficulty in treatment of $S$. parauberis infection by tetracyclines, especially those caused by serotype II strains.
\end{abstract}

Key words: Streptococcus parauberis, Paralichthys olivaceus, Japanese flounder, drug resistance, $\operatorname{tet}(\mathrm{S}), \operatorname{tet}(\mathrm{M}), \operatorname{erm}(\mathrm{B})$

Williams and Collins (1990) proposed a new species, Streptococcus parauberis, for the genotype II group of $S$. uberis, an etiologic agent of bovine mastitis. Doménech et al. (1996) was the first to identify $S$. parauberis as a fish pathogen for the isolates from diseased turbot Scophthalmus maximus by analyzing the 16S rRNA gene. Another group reported that this pathogen caused high economic losses in turbot culture in Spain (Toranzo et al., 1995). Since then, streptococcicosis caused by $S$. parauberis had been limited to turbot and Japanese flounder Paralichthys olivaceus cultured in Spain and Korea, respectively (Toranzo et al., 2005; Baeck et al., 2006). In Japan S. parauberis has emerged as one of the main bacterial pathogens in Japanese flounder since 2002. Based on a serological investigation, two serotypes, termed I and II, were proposed in Japanese isolates of $S$. parauberis (Kanai et al., 2009).

For the control of streptococcal infections in Japanese flounder in Japan, the usage of tetracyclines is the only way approved by the Ministry of Agriculture, For-

\footnotetext{
* Corresponding author

E-mail:kanai@nagasaki-u.ac.jp
}

estry and Fisheries (http://www.maff.go.jp/j/syouan/ suisan/suisan_yobo/pdf/suisan_iyakuhin.pdf). Tetracyclines as broad-spectrum agents have been widely used for disease treatment in aquaculture in Japan (Kusuda and Salati, 1993; Sano, 1998). The high frequency in detection of tetracycline-resistant bacteria has been reported among various fish pathogens and mariculture environments (Aoki and Takahashi, 1987; Kusuda and Salati, 1993; Sano, 1998; Nonaka and Suzuki, 2002; Kim et al., 2004; Maki et al., 2008). Occurrence of tetracycline resistance among bacterial species is commonly due to three principal mechanisms; 1) efflux of tetracyclines, 2) an allosteric disruption of tetracycline binding site(s), namely ribosomal protection (RP), and 3) tetracycline-inactivating enzymes (Chopra and Roberts, 2001; Roberts, 2005). There are currently approximate 40 different tetracycline resistance determinants. In streptococci the common tetracycline resistance determinants are related to Gram-positive species tet genes, such as tet $(\mathrm{K})$ and $\operatorname{tet}(\mathrm{L})$ efflux genes and $\operatorname{tet}(\mathrm{M})$, tet $(\mathrm{O})$ and tet(S) RP genes (Chopra and Roberts, 2001; Roberts, 2005). Among these tet $(\mathrm{M})$ has the widest host range up to 42 genera. The association of tet $(\mathrm{M})$, int (integrase) and xis (excisase) genes characterizes the 
Tn916 -Tn 1545 family (Clewell et al., 1995).

Investigation of the antimicrobial susceptibility of isolates is needed for the treatment of diseases, particularly susceptibility to tetracyclines in the case of $S$. parauberis. The aim of this study was to analyze the antimicrobial susceptibility of $S$. paraubeirs strains isolated from Japanese flounder in Japan. We also screened the resistance determinants among resistant strains.

\section{Materials and Methods}

Bacterial strains and culture media

Sixty-four $S$. parauberis strains isolated from Japanese flounder between 2002 and 2007 at commercial aquaculture sites in the western districts of Japan were used in this study (Table 1). Identification of the strains was performed by PCR analysis of $S$. parauberis $23 S$ rDNA (Mata et al., 2004), and serotyping was carried out by slide agglutination test with anti-S. parauberis type I and II rabbit antisera (Kanai et al., 2009). Of the 64 strains, 44 and 20 were found to belong to serotype I and II, respectively. Enterococcus faecalis FA2-2 (Shiojima et al., 1997) was used as a recipient for conjugation of plasmids, and E. faecalis CG110 containing Tn916 (Shimoji et al., 1994) as a positive control for investigating the presence of Tn916 family transposons by PCR and Southern hybridization. S. parauberis and $E$. faecalis strains were grown in Todd Hewitt (TH) (Difco) broth or agar. Stock cultures were stored at $-80^{\circ} \mathrm{C}$ in TH broth containing $10 \%(\mathrm{v} / \mathrm{v})$ glycerol.

\section{Determination of minimum inhibitory concentration}

Minimum inhibitory concentrations (MICs) of antimicrobial agents were determined by the agar dilution method (Japanese Society of Antimicrobials for Animals, the Committee, 2003) using sensitivity test broth (Nissui) containing $1.5 \%$ agar. The following nine antimicrobial agents were tested: ampicillin (ABPC), chloramphenicol
$(\mathrm{CP})$, erythromycin (EM), kanamycin $(\mathrm{KM})$, lincomycin (LCM), oxolinic acid (OA), oxytetracycline (OTC), sulfamonomethoxine (SMMX) and trimethoprim (TMP). The MIC values were determined after incubation at $28^{\circ} \mathrm{C}$ for $20 \mathrm{~h}$. Final concentrations of drugs were from 0.016 to $512 \mu \mathrm{g} / \mathrm{mL}$ for ABPC and EM and from 0.125 to $512 \mu \mathrm{g} / \mathrm{mL}$ for CP, KM, LCM, OA, OTC, SMMX and TMP.

\section{Screening for antimicrobial resistance and transposon-} associated genes

The presence of antimicrobial resistance and transposon-associated genes were screened by PCR. Oligonucleotide primer sets and PCR condition for detection of genes are listed in Table 2. Macrolideand tetracycline-resistant genes were tested on all resistant strains. They were also examined for the presence of int, xis, tnpA (transposase) and $\operatorname{tnp} R$ (resolvase); the former two genes were associated with conjugative transposons Tn916-Tn1545 family and the latter two were associated with Tn917 (Shaw and Clewell, 1985). Chromosomal and plasmid DNAs of each strain were prepared using Wizard Genomic DNA Purification kit (Promega) and QIAprep Miniprep kit (Qiagen), respectively, according to the manufacturer's protocols. PCR was performed using $50 \mathrm{ng}$ of chromosomal or plasmid DNA as template, $0.5 \mu \mathrm{m}$ of each primer, $5 \mu \mathrm{L}$ of $10 \times$ Ex Taq buffer $\left(\mathrm{Mg}^{2+}\right.$ plus), $8 \mu \mathrm{L}$ of dNTP mixture (0.2 mm each) and 1.25 U of Ex Taq DNA polymerase (Hot Start Version, Takara) up to a total volume of $50 \mu \mathrm{L}$ by adding deionized distilled water. The reaction condition varied according to the primers used and the size of product.

\section{Southern hybridization}

Based on the results of PCR, resistant strains were applied for Southern blot hybridization analysis. Chromosomal DNAs $(1.5 \mu \mathrm{g})$ or plasmid DNAs (500 ng) extracted from those strains were completely digested

Table 1. Number of Streptococcus parauberis strains used in this study

\begin{tabular}{|c|c|c|c|c|c|c|c|c|}
\hline \multirow{2}{*}{ Prefecture S } & \multirow{2}{*}{ Serotype } & \multicolumn{6}{|c|}{ Year } & \multirow{2}{*}{ Total } \\
\hline & & 2002 & 2003 & 2004 & 2005 & 2006 & 2007 & \\
\hline \multirow[t]{2}{*}{ Kagawa } & I & 5 & & 3 & 4 & & & 12 \\
\hline & II & 8 & & & & & & 8 \\
\hline \multirow[t]{2}{*}{ Ehime } & I & & & 2 & 16 & 1 & & 19 \\
\hline & II & & & & & & & \\
\hline \multirow[t]{2}{*}{ Oita } & I & & & & 4 & 4 & 5 & 13 \\
\hline & ॥ & & 2 & & 3 & 2 & 1 & 8 \\
\hline \multirow[t]{2}{*}{ Kagoshima } & I & & & & & & & \\
\hline & ॥ & & & & & 1 & & 1 \\
\hline \multirow[t]{2}{*}{ Nagasaki } & I & & & & & & & \\
\hline & II & & & & 1 & 2 & & 3 \\
\hline Total & & 13 & 2 & 5 & 28 & 10 & 6 & 64 \\
\hline
\end{tabular}


Table 2. Primers used for PCR detection of genes

\begin{tabular}{|c|c|c|c|c|}
\hline Target gene & Primer sequences $\left(5^{\prime}\right.$ to $\left.3^{\prime}\right)$ & PR fragment size (bp) & Annealing temperature $\left({ }^{\circ} \mathrm{C}\right)$ & Reference \\
\hline $\operatorname{erm}(\mathrm{A})$ & $\begin{array}{l}\text { GTTCAAGAACAATCAATACAGAG } \\
\text { GGATCAGGAAAAGGACATTTTAC }\end{array}$ & 420 & 52 & Lina et al., 1999 \\
\hline $\operatorname{erm}(\mathrm{B})$ & $\begin{array}{l}\text { GTAAACAGTTGACGATATTCTCG } \\
\text { CGTACCTTGGATATTCACCG }\end{array}$ & $224^{*}$ & 50 & Nagai et al., 2001 \\
\hline $\operatorname{erm}(\mathrm{C})$ & $\begin{array}{l}\text { GCTAATATTGTTTAAATCGTCAATTCC } \\
\text { GGATCAGGAAAAGGACATTTTAC }\end{array}$ & 359 & 52 & Lina et al., 1999 \\
\hline $\operatorname{mef}(\mathrm{A})$ & $\begin{array}{l}\text { AGTATCATTAATCACTAGTGC } \\
\text { TTCTTCTGGTACTAAAAGTGG }\end{array}$ & 345 & 52 & Sutcliffe et al., 1996 \\
\hline $\operatorname{tet}(\mathrm{K})$ & $\begin{array}{l}\text { TATTTTGGCTTTGTATTCTTTCAT } \\
\text { GCTATACCTGTTCCCTCTGATAA }\end{array}$ & 1,159 & 50 & Giovanetti et al., 2003 \\
\hline $\operatorname{tet}(\mathrm{L})$ & $\begin{array}{l}\text { ATAAATTGTTTCGGGTCGGTAAT } \\
\text { AACCAGCCAACTAATGACAATGAT }\end{array}$ & 1,077 & 50 & Giovanetti et al., 2003 \\
\hline $\operatorname{tet}(\mathrm{M})$ & $\begin{array}{l}\text { GTTAAATAGTGTTCTTGGAG } \\
\text { CTAAGATATGGCTCTAACAA }\end{array}$ & $657^{*}$ & 57 & Aarestrup et al., 2000 \\
\hline $\operatorname{tet}(\mathrm{O})$ & $\begin{array}{l}\text { AACTTAGGCATTCTGGCTCAC } \\
\text { TCCCACTGTTCCATATCGTCA }\end{array}$ & 515 & 55 & Jeric et al., 2002 \\
\hline $\operatorname{tet}(\mathrm{S})$ & $\begin{array}{l}\text { ATCAAGATATTAAGGAC } \\
\text { TTCTCTATGTGGTAATC }\end{array}$ & $573^{*}$ & 55 & Charpentier et al., 1993 \\
\hline int & $\begin{array}{l}\text { TGACACTCTGCCAGCTTTAC } \\
\text { CCATAGGAACTTGACGTTCG }\end{array}$ & 579 & 57 & Barbeyrac et al., 1996 \\
\hline$x i s$ & $\begin{array}{l}\text { AGCAGACTGACATTCCTA } \\
\text { GCGTCCAATGTATCTATAA }\end{array}$ & 193 & 55 & Amezaga et al., 2002 \\
\hline $\operatorname{tnp} A$ & $\begin{array}{l}\text { GCTTCCATGGGACTCGGGAC } \\
\text { GCTCCCAATTAATAGGAGA }\end{array}$ & 2,133 & 55 & Poyart et al., 2000 \\
\hline $\operatorname{tnp} R$ & $\begin{array}{l}\text { CCAAGGAGCTAAAGAGGTCCC } \\
\text { GTCCCGAGTCCCATGGAAGC }\end{array}$ & 1,547 & 55 & Poyart et al., 2000 \\
\hline
\end{tabular}

* Also used to obtain a specific probe for hybridization.

with HindIII. Digested DNAs were resolved by electrophoresis in $0.7 \%$ agarose gel, stained with ethidium bromide and photographed. After depurination, denaturation and neutralization of the gel, DNAs were transfered to Hybond $\mathrm{N}^{+}$membrane (GE Healthcare) by capillary blotting overnight. The membrane was rinsed in $5 \times \mathrm{SSC}$, fixed at $120^{\circ} \mathrm{C}$ for $30 \mathrm{~min}$ and prehybridized at $55^{\circ} \mathrm{C}$ for $30 \mathrm{~min}$ in DIG Easy Hyb (Roche). The membrane was then hybridized at $55^{\circ} \mathrm{C}$ with tet $(\mathrm{M})$, tet(S) or erm(B) probe which was gel-purified PCR fragment (Table 2) labeled with digoxigenin-11-dUTP by random priming using DIG-High Prime (Roche). Washings were under stringent conditions, and signals were detected by exposure of the membrane to Hyperfilm ECL (GE Healthcare).

\section{Conjugal transfer of plasmid}

Filter mating was carried out by using broth cultures of donor and recipient cells in logarithmic phase. Mixture of the donor and $E$. faecalis FA2-2 cells at a ratio of one donor $(50 \mu \mathrm{L})$ per 10 recipients $(500 \mu \mathrm{L})$ was collected on a sterilized membrane filter $(0.45 \mu \mathrm{m}$, Millipore), and the filter was incubated on a $5 \%$ horse blood agar plate at $28^{\circ} \mathrm{C}$ overnight. Transconjugants were selected on $\mathrm{TH}$ agar plates containing oxytetracycline $(30 \mu \mathrm{g} / \mathrm{mL})$, rifampicin $(25 \mu \mathrm{g} / \mathrm{mL})$ and fusidic acid $(25 \mu \mathrm{g} / \mathrm{mL})$ and incubated at $37^{\circ} \mathrm{C}$ overnight. Transfer frequencies were calculated as the number of transconjugants per donor cell. Twenty transconjugants were picked up for testing antibiotic resistance and some of them were used for plasmid DNA purification.

\section{Results}

Drug susceptibilities

Fig. 1 shows the susceptibilities of the 64 strains of $S$. parauberis to nine antimicrobial agents. The exhibitions of MIC distributions were termed as susceptible, intermediately resistant and highly resistant. The MICs of all strains were shown to be one group for CP, KM and TMP as susceptible, while for OA and SMMX as resistant. $S$. parauberis strains exhibited an intrinsic resistance to OA and SMMX. The MICs of both ABPC and LCM presented two groups, 59 strains were susceptible with MIC values of $\leqq 0.016$ to $0.063 \mu \mathrm{g} / \mathrm{mL}$ and 0.5 to $1 \mu \mathrm{g} / \mathrm{mL}$, and five strains were low resistant with MIC values of 0.5 to $1 \mu \mathrm{g} / \mathrm{mL}$ and $4 \mu \mathrm{g} / \mathrm{mL}$, respectively.

For EM and OTC, the MICs of the 64 strains were categorized to three groups, that is, 39 strains were susceptible, 20 strains were intermediately resistant to EM and OTC and five strains were highly resistant to EM and OTC. The highly-resistant strains were ABPC/ LCM-low resistant strains mentioned above. The EM/ OTC-intermediately-resistant group consisted with sero- 

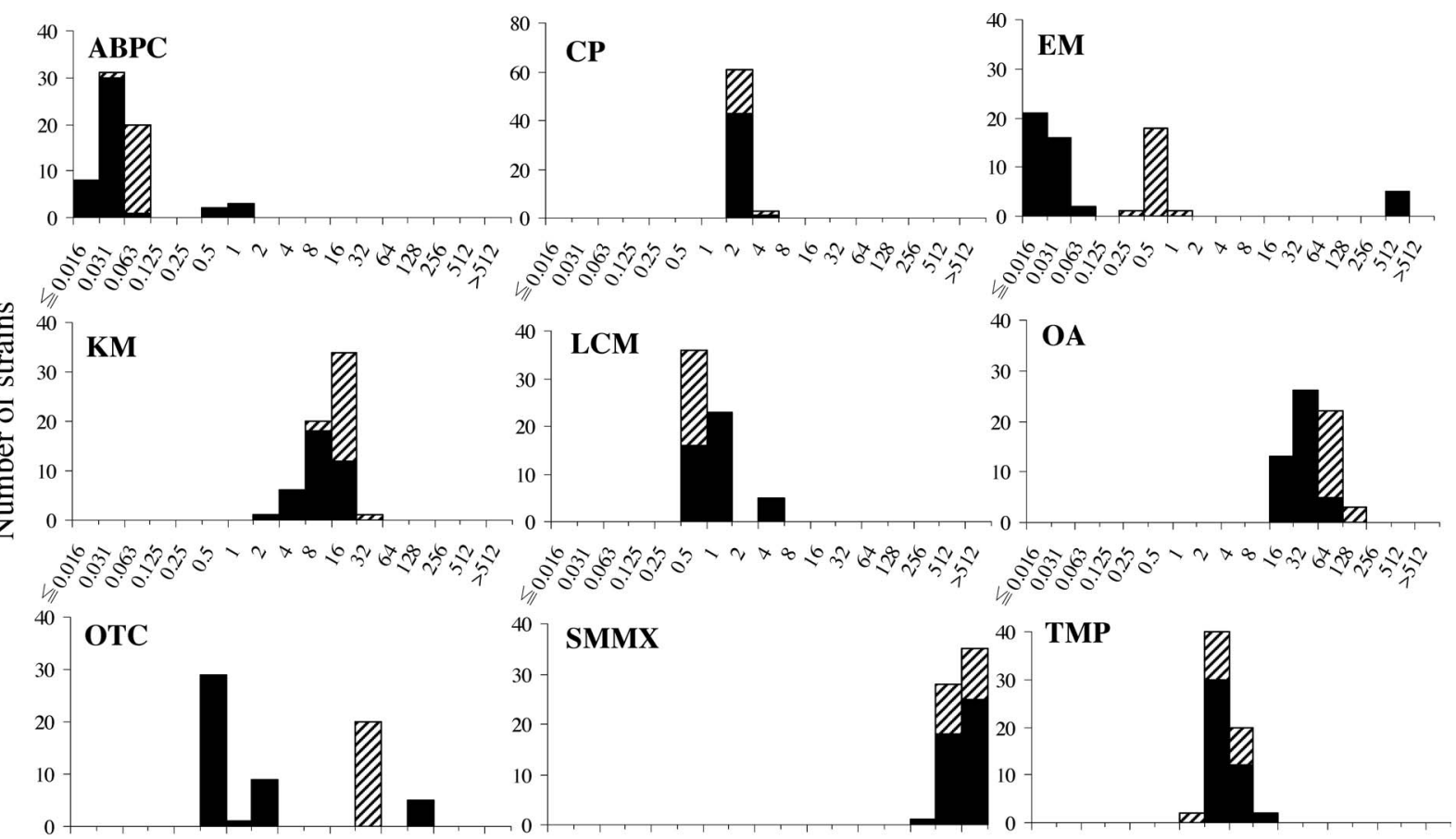

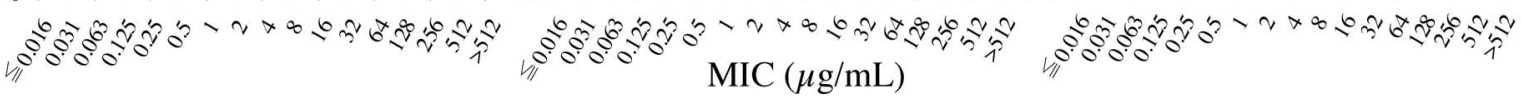

Fig. 1. MIC distributions of Streptococcus parauberis. Black bar, $S$. parauberis serotype I strains $(\mathrm{n}=44)$; Striped bar, $S$. parauberis serotype II strains $(n=20)$. ABPC, ampicillin; CP, chloramphenicol; EM, erythromycin; KM, kanamycin; LCM, lincomycin; OA, oxolinic acid; OTC, oxytetracycline; SMMX, sulfamonomethoxine; TMP, trimethoprim.

Table 3. Detection of gene markers in Streptococcus parauberis resistant strains

\begin{tabular}{|c|c|c|c|c|c|c|c|c|c|c|c|c|c|c|c|}
\hline \multirow{2}{*}{ Serotype } & \multirow{2}{*}{\multicolumn{2}{|c|}{$\begin{array}{c}\text { Strain no. } \begin{array}{c}\text { MIC to OTC } \\
(\mu \mathrm{g} / \mathrm{mL})\end{array}\end{array}$}} & \multicolumn{13}{|c|}{ Gene marker } \\
\hline & & & $\operatorname{erm}(\mathrm{A})$ & $\operatorname{erm}(\mathrm{B})$ & $\operatorname{erm}(\mathrm{C})$ & $\operatorname{mef}(\mathrm{A})$ & tet(K) & $\operatorname{tet}(\mathrm{L})$ & $\operatorname{tet}(\mathrm{M})$ & $\operatorname{tet}(\mathrm{O})$ & $\operatorname{tet}(\mathrm{S})$ & tnpR & $\operatorname{tnpA}$ & int & xis \\
\hline \multirow{5}{*}{ Type I } & 1 & 128 & - & + & - & - & - & - & - & - & + & - & - & - & - \\
\hline & 2 & 128 & - & + & - & - & - & - & - & - & + & - & - & - & - \\
\hline & 3 & 128 & - & + & - & - & - & - & - & - & + & - & - & - & - \\
\hline & 4 & 128 & - & + & - & - & - & - & - & - & + & - & - & - & - \\
\hline & 5 & 128 & - & + & - & - & - & - & - & - & + & - & - & - & - \\
\hline \multirow{20}{*}{ Type II } & 1 & 32 & - & - & - & - & - & - & + & - & - & - & - & + & + \\
\hline & 2 & 32 & - & - & - & - & - & - & + & - & - & - & - & + & + \\
\hline & 3 & 32 & - & - & - & - & - & - & + & - & - & - & - & + & + \\
\hline & 4 & 32 & - & - & - & - & - & - & + & - & - & - & - & + & + \\
\hline & 5 & 32 & - & - & - & - & - & - & + & - & - & - & - & + & + \\
\hline & 6 & 32 & - & - & - & - & - & - & + & - & - & - & - & + & + \\
\hline & 7 & 32 & - & - & - & - & - & - & + & - & - & - & - & + & + \\
\hline & 8 & 32 & - & - & - & - & - & - & + & - & - & - & - & + & + \\
\hline & 9 & 32 & - & - & - & - & - & - & + & - & - & - & - & + & + \\
\hline & 10 & 32 & - & - & - & - & - & - & + & - & - & - & - & + & + \\
\hline & 11 & 32 & - & - & - & - & - & - & + & - & - & - & - & + & + \\
\hline & 12 & 32 & - & - & - & - & - & - & + & - & - & - & - & + & + \\
\hline & 13 & 32 & - & - & - & - & - & - & + & - & - & - & - & + & + \\
\hline & 14 & 32 & - & - & - & - & - & - & + & - & - & - & - & + & + \\
\hline & 15 & 32 & - & - & - & - & - & - & + & - & - & - & - & + & + \\
\hline & 16 & 32 & - & - & - & - & - & - & + & - & - & - & - & + & + \\
\hline & 17 & 32 & - & - & - & - & - & - & + & - & - & - & - & + & + \\
\hline & 18 & 32 & - & - & - & - & - & - & + & - & - & - & - & + & + \\
\hline & 19 & 32 & - & - & - & - & - & - & + & - & - & - & - & + & + \\
\hline & 20 & 32 & - & - & - & - & - & - & + & - & - & - & - & + & + \\
\hline
\end{tabular}


type II strains, while the EM/OTC-highly-resistant group consisted with serotype I strains. Additionally, OTCsusceptible strains exhibited two peaks; the strains derived from Shikoku island (Kagawa and Ehime Prefectures) showed a lower MIC value against OTC $(0.5 \mu \mathrm{g} /$ $\mathrm{mL}$ ) than those from Kyushu island (Oita Prefecture) (1 to $2 \mu \mathrm{g} / \mathrm{mL})$.

\section{Detection of genes}

$\operatorname{erm}(\mathrm{A}) \operatorname{erm}(\mathrm{C})$ or $\operatorname{mef}(\mathrm{A})$ was not detected in 25 EM-intermediately- and highly-resistant strains, while the five EM-highly-resistant strains gave the expected 224bp PCR amplification product of erm(B). Tn917-related genes, tnpA or tnpR, were not detected in any of the EMresistant strains (Table 3 ).

Among 25 OTC-resistant strains, tet(M) and tet(S) genes were detected in 20 serotype II and five serotype I highly-resistant strains, respectively. int and xis genes of the Tn916 family were also detected in 20 serotype II strains (Table 3 ). All of the 20 serotype II strains yielded the same PCR reactions for int and xis genes as E. faecalis CG110, the positive control of Tn916 (Table 3).

\section{Localization of resistance genes}

PCR-amplified products of antimicrobial resistance genes, tet(S), erm $(\mathrm{B})$ and tet $(\mathrm{M})$, were used as probes to hybridize with the DNAs from resistant strains. Plasmid profiling of the five EM/ OTC-highly-resistant strains showed that these strains possessed one plasmid with an approximate size of $11 \mathrm{~kb}$ (data not shown). Hindlll digestion patterns of the plasmids from the five strains were identical and tet(S) was detected on the plasmids (Fig. 2). The erm(B) probe hybridized with the chromosomal DNAs of the tet(S)-positive strains (Fig. 3). These five strains came from the same prefecture but were isolated at different aquaculture sites. For the 20 OTC-intermediately-resistant serotype II strains, a 7.2-kb HindIII-digested fragment of the chromosomal

\section{Panel I Panel II}

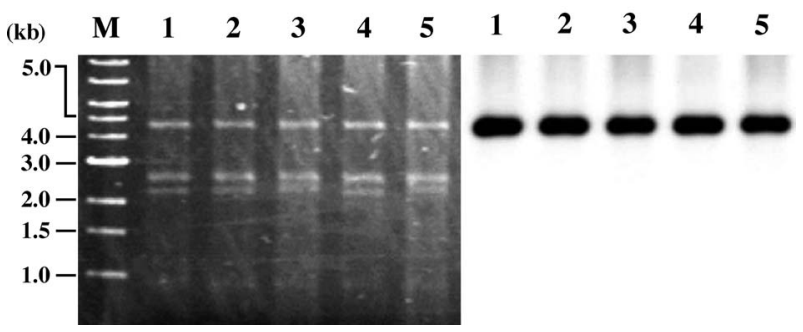

Fig. 2. HindllI-digested plasmid DNAs from EM/OTC-highlyresistant Streptococcus parauberis serotype I strains (panel I) and Southern blot hybridization analysis of HindIII-digested plasmid DNAs with tet(S) probe (panel II). Lane M, DNA size marker (1 kb DNA ladder, New England Biolabs); Lanes 1 to 5, EM/OTChighly-resistant $S$. parauberis serotype I strains No. 1 to 5 .

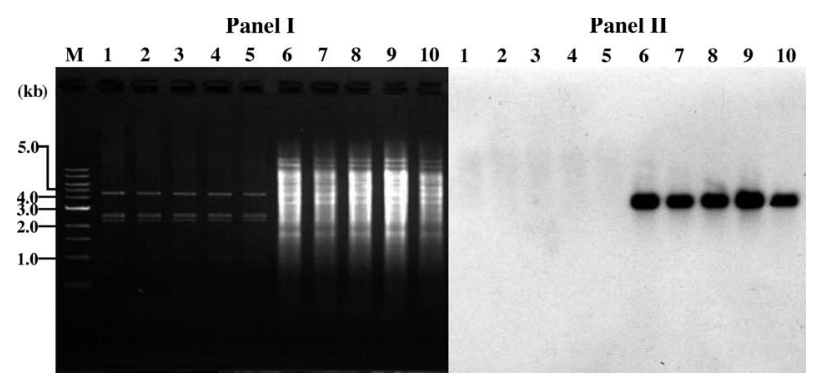

Fig. 3. Hindlll-digested plasmid (lanes 1-5) and chromosomal (lanes 6-10) DNAs from EM/OTC-highly-resistant Streptococcus pararuberis strains (panel I) and Southern blot hybridization analysis of Hindlll-digested plasmid (lanes 1-5) and chromosomal (lanes 6-10) DNAs with erm(B) probe (panel II). Lane M, DNA size marker (1 kb DNA ladder, New England Biolabs); Lanes 1 to 5, EM/OTC-highly-resistant $S$. parauberis strains No. 1 to 5 .

DNAs showed strong signal with the tet $(\mathrm{M})$ probe (data not shown). The reference strain, E. faecalis CG110, also yielded the positive signal.

\section{Conjugal transfer of tetracycline-resistant plasmid}

Conjugation experiments were carried out on the five OTC-highly-resistant strains with the plasmid-free recipient strain, E. faecalis FA2-2. In transconjugants from each donor, the tet(S)-positive plasmids were detected, and the size and HindIII restriction profile were the same as that in the respective donor strain. From these results it is concluded that the plasmid is a conjugative plasmid. The transfer frequency of the plasmid from each donor to $E$. faecalis FA2-2 was calculated at about $10^{-8}$ per donor cell by filter mating.

\section{Discussion}

In this study MIC values of susceptible strains of $S$. parauberis against ABPC ( $\leqq 0.016$ to $0.063 \mu \mathrm{g} / \mathrm{mL}$ ), EM ( $\leqq 0.016$ to $0.063 \mu \mathrm{g} / \mathrm{mL}$ ) and OTC (0.5 to $2 \mu \mathrm{g} / \mathrm{mL}$ ) were comparable to those of $S$. iniae, another important pathogen of streptococcicosis in Japanese flounder, whose MIC values were reported to be 0.00625 to 0.025 $\mu \mathrm{g} / \mathrm{mL}, 0.05 \mu \mathrm{g} / \mathrm{mL}$ and $0.39 \mu \mathrm{g} / \mathrm{mL}$, respectively (Sako, 1993). It is interesting that MIC values of susceptible strains derived from Shikoku island (Kagawa and Ehime Prefectures) against OTC were somewhat lower than those of Kyushu island (Oita Prefecture). These differences in susceptibility to OTC might result from variations in history of tetracycline consumptions in each geographical area.

In this study multiple drug resistant strains of $S$. parauberis were found among the serotype I strains tested. They were isolated at different aquaculture areas in one prefecture and were highly resistant to EM and OTC. Macrolide antimicrobials are not approved for administrating to Japanese flounder in Japan, but 
they have been used for treating streptococcicosis causing by Lactococcus garvieae in yellowtail Seriola quinqueradiata for many years. Several published works showed that $L$. garvieae strains isolated from yellowtail carried transferable R-plasmid on which erm(B) and tet(S) were integrated (Aoki et al., 1990; Maki et al., 2008). In addition, L. garvieae is also one of the pathogens causing streptococcicosis in cultured Japanese flounder (Fukuda, 2003). Taken together, horizontal spread of resistance genes between streptococci and lactococci might have occurred in aquaculture environment. During preparing this manuscript one serotype I strain of $S$. parauberis that was highly resistant to OTC but susceptible to EM was found in newly collected strains. This strain was isolated in a prefecture different from the prefecture where the EM/OTChighly-resistant strains were isolated. From the strain one plasmid was detected, the size and HindlII-digested pattern of which were the same as those of plasmids mentioned above (data not shown). This suggests that the conjugative plasmid encoding tet(S) is conserved and disseminated in western Japan.

In this study tet(M), int and xis genes were detected in all of serotype II strains. These genes are known to associate with Tn916-Tn1545 family transposons (Clewell et al., 1995; Chopra and Roberts, 2001). So it is supposed that Tn916-related element presents on the chromosomes of $S$. parauberis serotype II strains. We are now investigating the genetic structure of the Tn916related element. All of the serotype II strains also showed intermediately resistant to EM. In streptococci, some of mobile genetic elements carrying tet(M) also harbor macrolide resistance gene, erm(B), such as Tn1545 and Tn6002 (Cochetti et al., 2008). In this study, however, detection of $S$. parauberis serotype II strains for EM resistance genes was failed. Accordingly, these strains may have different mechanism for EM resistance.

Our results showed the presence of different mechanisms in acquisition of OTC resistance between $S$. parauberis serotype I and II. Serotype I strains contained a conjugative plasmid encoding tet(S) gene, while serotype II strains possessed Tn916-related element harboring tet( $\mathrm{M})$ gene. Due to the dissemination of the OTC-resistant strains it is likely that the therapy of $S$. parauberis infection in cultured Japanese flounder will become more difficult because of only relying on tetracyclines. In order to control the disease further investigation is needed on the mechanism of transfer and spread of the tetracycline resistance determinants. Likewise, preventive measures aiming at different serotypes of $S$. parauberis should be developed to minimize the usage of tetracyclines, such as immunoprophylaxis.

\section{Acknowledgements}

We thank Prof. Yasuyoshi Ike (Graduate School of Medicine, Gunma University, Japan) and Prof. Takashi Aoki (Graduate School of Marine Science and Technology, Tokyo University of Marine Science and Technology, Japan) for providing E. faecalis FA2-2 and useful instructions. We also thank staffs of Kagawa Prefectural Fisheries Experimental Station, Ehime Prefectural Fish Disease Control Center, Ehime Prefectural Chuyo Fisheries Experimental Station, Fisheries Research Institute, Oita Prefectural Agriculture, Forestry and Fisheries Research Center and Kagoshima Prefectural Fisheries Technology and Development Center for their providing $S$. parauberis strains.

\section{References}

Aarestrup, F. M., Y. Agerso, P. Gerner-Smidt, M. Madsen and L. B. Jensen (2000): Comparison of antimicrobial resistance phenotypes and resistance genes in phenotypes and resistance genes in Enterococcus faecalis and Enterococcus faecium from humans in the community, broilers, and pigs in Denmark. Diagn. Microbiol. Infect. Dis., 37, 127137.

Amezaga, M. R., P. E. Carter, P. Cash and H. Mckenzie (2002): Molecular epidemiology of erythromycin resistance in Streptococcus pneumoniae isolates from blood and noninvasive sites. J. Clin. Microbiol., 40, 3313-3318.

Aoki, T. and A. Takahashi (1987): Class D tetracycline resistance determinants of $\mathrm{R}$ plasmids from the fish pathogens Aeromonas hydrophila, Edwardsiella tarda, and Pasteurella piscicida. Antimicrob. Agents Chemother., 31, $1278-1280$.

Aoki, T., K. Takami and T. Kitao (1990): Drug resistance in a non-hemolytic Streptococcus $s p$. isolated from cultured yellowtail Seriola quinqueradiata. Dis. Aquat. Org., 8, 171177.

Baeck, G. W., J. H. Kim, D. K. Gomez and S. C. Park (2006): Isolation and characterization of Streptococcus sp. from diseased flounder (Paralichthys olivaceus) in Jeju Island. J. Vet. Sci., 7, 53-58.

Barbeyrac, B. D., M. Dupon, P. Rodriguez, H. Renaudin and C. Bebear (1996): A Tn1545-like transposon carries the tet(M) gene in tetracycline resistant strains of Bacteroides ureolyticus as well as Ureaplasma urealyticum but not Neisseria gonorrhoeae. J. Antimicrob. Chemother., 37, 223-232.

Charpentier, E., G. Gerbaud and P. Courvalin (1993): Characterization of a new class of tetracycline-resistance gene tet(S) in Listeria monocytogenes BM4210. Gene, 131, 27-34.

Chopra, I. and M. Roberts (2001): Tetracycline antibiotics: Mode of action, applications, molecular biology, and epidemiology of bacterial resistance. Microbiol. Mol. Biol. Rev., 65, 232-260.

Clewell, D. B., S. E. Flannagan and D. D. Jaworski (1995): Unconstrained bacterial promiscuity: The Tn916-Tn1545 family of conjugative transposons. Trends Microbiol., 3, 229-236.

Cochetti, I., E. Tili, M. Mingoia, P. E. Varaldo and M. P. Montanari (2008): erm(B)-carrying elements in tetracyclineresistant pneumococci and correspondence between Tn1545 and Tn6003. Antimicrob. Agents Chemother., 52, 
$1285-1290$.

Doménech, A., J. F. Fernández-Garayzábal, C. Pascual, J. A. Garcia, M. T. Cutuli, M. A. Moreno, M. D. Collins and L. Dominguez (1996): Streptococcosis in cultured turbot, Scopthalmus maximus (L.), associated with Streptococcus parauberis. J. Fish Dis., 19, 33-38.

Fukuda, Y. (2003): Drug susceptibility of fish-pathogenic bacteria isolated from cultured marine fishes in Oita prefecture from 1990 to 2001. Bull. Oita Inst. Mar. Fish. Sci., 4, 2550. (In Japanese)

Giovanetti, E., A. Brenciani, R. Lupidi, M. C. Roberts and P. E. Varaldo (2003): Presence of the tet(O) gene in erythromycin- and tetracycline-resistant strains of Streptococcus pyogenes and linkage with either the $\operatorname{mef}(\mathrm{A})$ or the erm(A) gene. Antimicrob. Agents Chemother., 47, 2844-2849.

Japanese Society of Antimicrobials for Animals, the Committee (2003): Revision of the determination method of the minimum inhibitory concentration (MIC) of antimicrobials against bacteria isolated from animals. Fish Pathol., 39, 58-67.

Jeric, P. E., H. Lopardo, P. Vidal, S. Arduino, A. Fernandez, B. E. Orman, D. O. Sordelli and D. Centron (2002): Multicenter study on spreading of the tet(M) gene in tetracycline-resistant Streptococcus group $\mathrm{G}$ and $\mathrm{C}$ isolates in Argentina. Antimicrob. Agents Chemother., 46, 239-241.

Kanai, K., M. Yamada, F. Meng, I. Takahashi, T. Nagano, H. Kawakami, S. Matsuoka, Y. Fukuda, I. Takami, H. Nakano, T. Hirae, K. Shutou and T. Honma (2009): Serological differentiation of Streptococcus parauberis strains isolated from cultured Japanese flounder in Japan. Fish Pathol., 44, 10-16. (In Japanese with English abstract)

Kim, S. R., L. Nonaka and S. Suzuki (2004): Occurrence of tetracycline resistance genes tet(M) and tet(S) in bacteria from marine aquaculture sites. FEMS Microbiol. Lett., 237, 147-156.

Kusuda, R. and F. Salati (1993): Major bacterial diseases affecting mariculture in Japan. Ann. Rev. Fish Dis., 3, 6585.

Lina, G., A. Quaglia, M. E. Reverdy, R. Leclercq, F. Vandenesch and J. Etienne (1999): Distribution of genes encoding resistance to macrolides, lincosamides, and streptogramins among staphylococci. Antimicrob. Agents Chemother., 43, 1062-1066.

Maki, T., I. Hirono, H. Kondo and T. Aoki (2008): Drug resistance mechanism of the fish-pathogenic bacterium Lactococcus garvieae. J. Fish Dis., 31, 461-468.

Mata, A. I., A. Gibello, A. Casamayor, M. M. Blanco, L. Dominguez and J. F. Fernandez-Garayzabal (2004): Multiplex PCR assay for detection of bacterial pathogens associated with warm-water streptococcosis in fish. Appl. Environ. Microbiol., 70, 3183-3187.
Nagai, K., Y. Shibasaki, K. Hasegawa, T. A. Davies, M. R. Jacobs, K. Ubukata and P. C. Appelbaum (2001): Evaluation of PCR primers to screen for Streptococcus pneumoniae isolates and beta-lactam resistance, and to detect common macrolide resistance determinants. J. Antimicrob. Chemother., 48, 915-918.

Nonaka, L. and S. Suzuki (2002): New $\mathrm{Mg}^{2+}$-dependent oxytetracycline resistance determinant tet 34 in Vibrio isolates from marine fish intestinal contents. Antimicrob. Agents Chemother., 46, 1550-1552.

Poyart, C., G. Quesne, P. Acar, P. Berche and P. Trieu-Cuot (2000): Characterization of the Tn916-like transposon Tn3872 in a strain of Abiotrophia defective (Streptococcus defective) causing sequential episodes of endocarditis in a child. Antimicrob. Agents Chemother., 44, 790-793.

Roberts, M. C. (2005): Update on acquired tetracycline resistance genes. FEMS Microbiol. Lett., 245, 195-203.

Sako, H. (1993): In vitro and vivo susceptibility of Streptococcus iniae, isolated from diseased fish, to antimicrobial agents. SUISANZOSHOKU, 41, 397-404. (In Japanese with English abstract)

Sano, T. (1998): Control of fish disease, and the use of drugs and vaccines in Japan. J. Appl. Ichthyol., 14, 131-137.

Shaw, J. H. and D. B. Clewell (1985): Complete nucleotide sequence of macrolide-lincosamide-streptogramin B-resistance transposon Tn917 in Streptococcus faecalis. J. Bacteriol., 164, 782-796.

Shimoji, Y., Y. Yokomizo, T. Sekizaki, Y. Mori and M. Kubo (1994): Presence of a capsule in Erysipelothrix rhusiopathiae and its relationship to virulence for mice. Infect. Immun., 62, 2806-2810.

Shiojima, M., H. Tomita, K. Tanimoto, S. Fujimoto and Y. Ike (1997): High-level plasmid-mediated gentamicin resistance and pheromone response of plasmids present in clinical isolates of Enterococcus faecalis. Antimicrob. Agents Chemother., 41, 702-705.

Sutcliffe, J., T. Grebe, A. Tait-Kamradt and L. Wondrack (1996): Detection of erythromycin-resistant determinants by PCR. Antimicrob. Agents Chemother., 40, 2562-2566.

Toranzo, A. E., J. M. Cutrín, S. Núñez, J. L. Romalde and J. L. Barja (1995): Antigenic characterization of Enterococcus strains pathogenic for turbot and their relationship with other Gram-positive bacteria. Dis. Aquat. Org., 21, 187191.

Toranzo, A. E., B. Magariños and J. L. Romalde (2005): A review of the main bacterial fish diseases in mariculture systems. Aquaculture, 246, 37-61.

Williams, A. M. and M. D. Collins (1990): Molecular taxonomic studies on Streptococcus uberis types I and II. Description of Streptococcus parauberis sp. nov. J. Appl. Bacteriol., 68, 485-490. 